\title{
Well-Being, Psychosocial Problems and Social Interaction Anxiety in Children
}

\author{
Budithi Sushma $^{1}$, Gadiraju Padmaja ${ }^{2}$, Swati Agarwal $^{3}$
}

\section{ABSTRACT}

Social anxiety is a disorder that most often arises in childhood. This results in social problems in childhood as well as adulthood. Institutionalised children have been known to display many emotional and behavioural problems but the role of social anxiety in these problems has not been explored. The present study assessed the effect of institutional care on social interaction anxiety in children and further assessed the role of social interaction anxiety in emotional and behavioural problems in children. The relationship between social interaction anxiety, psychosocial problems and well being in institutionalised and non institutionalised children was also analysed in the study. 116 children between the age range of 12 to 15 years, which included 40 institutionalised and 76 non institutionalised children, were assessed using the Social Interaction Anxiety Scale (SIAS), Strengths and Difficulties Questionnaires (SDQ) and Adolescent Well being Scale. It was found that type of care and gender did play a role in social interaction anxiety. Further, social interaction anxiety was associated with psychosocial problems and well being in children. Programs targeting creation of awareness in the caretakers/supervisors in the institutions in this area, and programs aimed at improving the interactional skills of institutionalised children appear to be essential.

Keywords: Social Interaction Anxiety, Well Being, Psychosocial Problems, Children, Type Of Care

Institutional care is "a group living arrangement for more than ten children, without parents or surrogate parents, in which care is provided by a much smaller number of paid adult carers" (Browne, 2009). It is marked by a regimental system of care evident from Browne's (2009) statement that "residential care implies an organised, routine and impersonal structure to the living arrangements for children (eg, all children sleep, eat and toilet at the same time) and a

\footnotetext{
${ }^{1}$ Assistant Professors at the Centre for Health Psychology, University of Hyderabad, India

${ }^{2}$ Assistant Professors at the Centre for Health Psychology, University of Hyderabad, India

${ }^{3}$ Assistant Professor at the St. Francis College for Women, Hyderabad, India

*Responding Author

(C) 2016 I B Sushma, G Padmaja, S Agarwal; licensee IJIP. This is an Open Access Research distributed under the terms of the Creative Commons Attribution License (http://creativecommons.org/licenses/by/2.0), which permits unrestricted use, distribution, and reproduction in any Medium, provided the original work is properly cited.
} 


\section{Well Being, Psychosocial Problems and Social Interaction Anxiety in Children}

professional relationship, rather than parental relationship, between the adults and children”. He further states that a child can be considered to be under institutional care or is said to be institutionalized if he/she has been under institutional care for more than three months.

The Government of India's Ministry of Women and Child Development provides different kinds of institutions for children based on need and designation. These include Observation Homes, where children accused of crime wait for their cases to be heard; Special Homes where juveniles are committed as per the decision of Juvenile Justice Board and Children's Homes for children whose parents are unable to provide adequate care. The children stay in these homes until they are able to return to their family, are placed in a different facility or turn 18. In the present study children from Children homes were included.

Children's Homes in India include those overseen by the government, but mostly consist of homes run by civil society organizations or Non Governmental Organizations. These homes may include children from ages of 5 upto 18 years. The children are placed in the institutions by the government, extended family members, neighbours, siblings or parents themselves if they are unable to care for the children themselves. The children may be orphans, victims of physical and emotional abuse, street children, runaways or abandoned children. Efforts are made to reunite the children with their families and in instances where this is not possible, the children continue to reside in the institutions until they become adults, that is, turn 18 years.

In many institutions the number of children is far more than the number for whom adequate care can be provided. The living space may not be able to accommodate all the children (Mullan, McAlister, Rollock and Fitzsimons; 2007). Basic amenities may be insufficient for all the children residing there. Also, the caregiver child ratio may be large. Such conditions add to the risks faced by institutionalized children. The impact of institutionalisation is greater on children who have been living in institutions for long periods of time and from an early age (Van IJzendoorn, Luijk \& Juffer, 2008; Sonuga-Barke, et al., 2008). In the vast majority of cases, institutional care involves large numbers of children living in an artificial setting which effectively detaches them, not only from their own immediate and extended family and from their community of origin, but also from meaningful interaction with the community in which the institution is located.

Research on institutionalized children categorically states the negative effect of institutional care on the physiological, psychological and social health of the children (Nelson, Zeanah, Fox, Marshall, Smyke and Guthrie, 2007; Zeanah, Smyke, Koga, Carlson, \& the BEIP core group, 2005; Ford, Vostanis, Meltzer, \& Goodman, 2007). Despite the adverse impact of institutionalization, this is a common alternative care option for destitute and orphaned children in India. There is no clear data on the exact figure of institutionalized children but one estimate 


\section{Well Being, Psychosocial Problems and Social Interaction Anxiety in Children}

by an organization, which has worked across ten states and more than 100 districts of India, puts the number at 4.5 million children (Aangan Trust, 2010).

The prevalence of psychological, emotional, cognitive, behavioural problems is higher in institutionalized children than those who have been living with their parents (Erol, Simsek, and Münir, 2010; Sushma, Padmaja \& Agarwal, 2014). Institutionalized children have been found to have lower intelligence, attention deficit, memory difficulties, emotional problems, poor social skills, behavioural issues, inadequate coping skills, mental health problems, etc (Nelson, Zeanah, Fox, Marshall, Smyke and Guthrie, 2007; Zeanah, Smyke, Koga, Carlson, \& the BEIP core group, 2005; Ford, Vostanis, Meltzer, \& Goodman, 2007; Mullan, Mcalister, Rollock and Fitzsimons (2007)). Though institutional care is aimed at providing protection and care to the children this may not always be the case.

Social skills and behavioural problems are a common problem area for children in institutions. Though it is widely accepted that children in institutions lack social skills, there are few studies looking into it. Children in institutions are reported to suffer from mental health problems, including anxiety disorder, but social anxiety has not been explored much by researchers (AttarSchwartz, 2007; Ford, Vostanis, Metzer and Goodman (2007).

Anxiety is an emotion characterized by feelings of tension, worried thoughts and physical changes like increased blood pressure (APA, 2014). It is a common experience with everyone undergoing it at some point in their lives. However, in many instances when this anxiety is debilitating, chronic, disruptive of everyday life, causing extreme distress and preventing growth then it is a cause of concern and requires professional treatment.

Social anxiety is a consequence of belief of negative appraisal by others in social situations. People may believe themselves to lack or have inadequate social skills needed in varied social situations. This feeling or belief of inadequacy may consequently cause them to fear social situations and even avoid them. People with this anxiety may also believe that their behaviour may be inappropriate in the given social situation that may result in negative reactions and evaluation from others around them. Apprehension about possible humiliation, ridicule and embarrassment among or in front of a group of people causes intense anxiety in these people.

Social anxiety has been proposed to be composed of two interrelated dimensions by Mattick \& Clarke, (1998) as cited by Kashdan (2004). Social interaction anxiety is defined as the fear and avoidance of meeting, interacting, and expressing oneself with others. Social observation anxiety is defined as the fear and avoidance of social situations where one is performing or being observed. However, most studies look into social anxiety as a whole. At the same time as social interactions are a dominant part of social life, they are also a dominant aspect in the study of social anxiety. The corresponding disorder for social anxiety as described in the DSM 


\section{Well Being, Psychosocial Problems and Social Interaction Anxiety in Children}

classification is called as Social Anxiety Disorder (SAD). For a person to be diagnosed with SAD he has to have been experiencing the symptoms for social anxiety for at least a period of 6 months and it has been interfering significantly with his normal routine, occupational, academic, social functioning and family life.

Social anxiety often starts to arise in childhood and early adolescence. However, this may be confused with shyness. People may also assume that the child who has social anxiety is reserved or an introvert by nature and avoidance of social situation is a preference or choice not a compulsion. Even those children who suffer from anxiety about social interactions may not seek help for it for a long time until they reach adulthood. So detection of social anxiety is difficult. High socially anxious children do not have different skills and behaviour from their peers but perceive differences and hence display high scores on self report measure of social anxiety (Greco and Morris, 2002; Lindhout, Markus, Hoogendijk and Boer, 2009; Festa and Ginsburg, 2011).

Social anxiety is an internal state and hence may not be detectable in most situations unless the person suffering from it reports it. It may cause emotional problems (Muris, Schmidt and Merckelbach, 2000) and also affect outward behavior (Biederman et al, 2001). In certain cases children who have social anxiety may display externalized problems that can be traced to the anxiety of social interaction. Some children exhibit defiant behaviour, conduct problems, peer problems that are a consequent of their internal anxiety.

Social anxiety can have adverse effects on the child's growth and development. Research has found links to poor physical and psychological health in those with social anxiety. Some problems associated with social anxiety include loneliness, low self-esteem, depression, substance misuse and reduced academic and school performance. Ginsburg, Greca and Silverman (1998) in their study of 154 children with diagnosed anxiety problems found that social anxiety was associated with impairments in emotional and social functioning. Further, the researchers found that those children who had high levels of social anxiety reported lower levels of social acceptance, low global self esteem and more negative peer interactions. These problems may hamper their growth and prevent them from reaching their full potential.

As Karevold, Ystrom, Coplan, Sanson and Mathiesen (2012) showed, shyness, though not the same as social anxiety, may in certain cases also be a manifestation of Social Anxiety Disorder. Their study of 921 children over a period of 11 years in a prospective longitudinal design found that shyness predicted poor social skills and higher levels of anxiety and depression symptoms in adolescence. Further, contrary to common belief that shyness ends with adulthood and is limited mostly to children, shyness does have repercussions in adulthood as well as Caspi, Elder and Bem (1988) found. They followed children who were shy in their childhood, 30 years into their adulthood and found that shy boys experience many impediments in relation to the milestones of 


\section{Well Being, Psychosocial Problems and Social Interaction Anxiety in Children}

adult life such as late entry into marriages and parenthood, lower occupational achievement and stability; while shy girls were more likely than their peers to follow a traditionally gendered life pattern which included marriage, childbearing and homemaking.

Phillips, McCartney and Scarr (1987) examined how the care received by a child in early childhood has an impact on his or her social development and found that the quality of child care did have an impact on their social development. The aspects of quality of care that influence social interaction anxiety include attachment with each of the parents (Bohlin, Hagekull and Rydell, 2000; Ollendick and Benoit, 2012), interactions with parents and siblings (Festa and Ginsburg, 2011; Ollendick and Benoit, 2012), family environment (Bandelow, Torrente, Wedekind, Broocks, Hajak and Ruther, 2004), parenting styles (Bandelow, et al., 2004; Lindhout, Markus, Hoogendijk and Boer, 2009), and beliefs. Ollendick and Benoit (2012) presented a parent child interactional model that explains how there is a complex and delicate interplay between parent and child factors that can result in social anxiety. However, the authors acknowledge that other factors outside this dyad, such as peers, school environment, etc., also play a role. Thus, it can be seen that care children receive from their parents influences the development, maintenance and progression and decline of social anxiety in them.

Studies that looked into the anxiety related to social interactions in children who are placed in alternative care such as kinship care, foster care, or institutional care appear to be sparse. Children who are under institutional care experience a care situation that is far removed from home based care. Institutional care is exemplified by regimental, structured life, with strict rules and regulations, limited time with an adult caretaker, limited private space and belonging. Many studies have been carried out on institutionalized children that establish the effect of this type of care on the psychosocial functioning of children. Children in institutions have been found to experience social problems (Şimşek, Erol, Oztop and Ozcan, 2010). But the role that social anxiety may be playing in these social problems does not seem to have been explored. The present study thus intended to determine the role that the type of care may have on social interaction anxiety in children. Further, the study also seeks to find out whether there is a correlation between social interaction anxiety and psychosocial problems such as internalizing problems and externalizing problems and well being in children, particularly institutionalised children.

\section{METHOD}

Design - Between subjects design was used to compare the two groups - one with high level of anxiety in social interactions and the other with low level of anxiety in social interactions; on various other factors such as internalizing problems, externalizing problems and well being/ depression. Correlation design was used to assess relationship among various variables. 


\section{Well Being, Psychosocial Problems and Social Interaction Anxiety in Children}

Participants - Children from an institution who were in the age range of 12 to 15 years were included. There were 18 girls and 22 boys leading to a total sample of 40 institutionalized children. Seventy six children from the same age group who were living with their parents were included from government run schools in Hyderabad. This home based care group or non institutionalised group included 37 boys and 39 girls.

Instruments- Social Interaction Anxiety Scale (Mattick and Clarke, 1998) has 20 items on a 5 point scale. The respondent has to state the extent to which a statement is true for him/her. The total possible score on this scale ranges from 0 to 80 . A score of over 34 indicates probable social phobia and a score of over 43 indicates probable social anxiety. These cutoffs are not meant for diagnostic purpose and are indicative of anxiety related to social interactions.

Strengths And Difficulties Questionnaire (SDQ) (Goodman, 1997) is a brief self report behavioural screening questionnaire for children between the ages of 11 to 16 years consisting of 25 items that measure both positive and negative aspects of five dimensions of behaviour: emotional symptoms (5 items), conduct problems (5 items), hyperactivity/inattention (5 items), peer relationship problems (5 items) and prosocial behaviour (5 items). The score of the first four dimensions added together give a difficulties score and the last dimension gives a strength score. The measure also includes an alternate three subscale division of the SDQ that divides SDQ into 'internalizing problems' (emotional and peer symptoms, 10 items), 'externalizing problems' (conduct and hyperactivity symptoms, 10 items) and the prosocial scale (5 items). Each of these items offers respondents three options and the respondent has to choose the option that best applies to him/her. The scoring and interpretation of the SDQ is as per the manual. The prosocial scale was not included in the present study.

The Adolescent Well Being Scale (Birleson, 1981) has 18 questions - each relating to different aspects of an adolescent's life, and how they feel about them. They are asked to indicate whether the statement applies to them most of the time, sometimes or never. It is for children between the ages of 11 to 16 years. The scoring and interpretation of the Adolescent Well Being Scale is as per the manual.

Statistical analysis - Two way ANOVA was used to determine the role of type of care and gender on social interaction anxiety. The participants were grouped into two groups based on their score on the social interaction anxiety scale - those having low level of social interaction anxiety in social interactions and those having high level of social interaction anxiety. The median was the classification criteria with the former group falling below the median and the latter group falling on or above the median. The levels of internalizing problems, externalizing problems and well being/ depression were compared between these two groups using independent $t$ test. Pearson's product moment correlation was used to calculate the correlation 


\section{Well Being, Psychosocial Problems and Social Interaction Anxiety in Children}

among social interaction anxiety, internalizing problems, externalizing problems and well being/depression.

\section{RESULTS}

Table 7 .

Summary ANOVA table for role of type of care and gender on social interaction anxiety

\begin{tabular}{lcccccc}
\hline \multicolumn{1}{c}{ Source } & SS & df & MS & F-stat & $p$ & Portial $\eta^{2}$ \\
\hline Type of care & 474.539 & 1 & 474.539 & 4.437 & $.037^{*}$ & .038 \\
Gender & 1020.541 & 1 & 1020.541 & 9.543 & $.003^{* *}$ & .079 \\
Interaction & 1.878 & 1 & 1.878 & .018 & .895 & .000 \\
Error & 11977.274 & 112 & 106.940 & & & \\
Total & 13472.784 & 115 & - & - & - & \\
\hline
\end{tabular}

$*_{p}=0.05, * *_{p}=0.01, * * *_{p}=0.001$

There was a main effect of type of care on social interaction anxiety as it yielded a significant $\mathrm{F}$ ratio as seen in table 1 . This indicates that children under institutional care $(\mathrm{M}=36.08$, S.D. $=$ 9.77) reported higher level of social interaction anxiety than children under home based care ( $M$ $=32.21$, S.D. $=11.18)$. There was also a main effect of gender on social interaction anxiety as the $\mathrm{F}$ ratio was found to be significant. This indicates significant differences with girls $(\mathrm{M}=$ 36.56, S.D. = 10.18) having higher social interaction anxiety than boys $(\mathrm{M}=30.63$, S.D. $=$ 10.71). The interaction effect of gender and type of care on social interaction anxiety was not significant.

\section{Table 2.}

Summary t table for psychosocial problems in children with low and high level of social interaction anxiety

\begin{tabular}{lccc}
\hline & \multicolumn{2}{c}{ Social interaction Anxiety } & \\
& Group A (low) & Group B (High) & $\mathrm{t}$ \\
Emotional problems & $3.34(2.00)$ & $4.59(1.74)$ & $3.56^{* * *}$ \\
Peer problems & $2.74(1.32)$ & $3.57(1.61)$ & $3.03^{* *}$ \\
Intemalizing Problems & $6.09(2.56)$ & $8.16(2.37)$ & $4.52^{* * *}$ \\
Hyperactivity & $2.66(1.68)$ & $3.59(2.01)$ & $2.71^{* *}$ \\
Conduct problems & $3.07(1.75)$ & $3.66(1.67)$ & 1.85 \\
Extemalizing Problems & $5.72(2.55)$ & $7.24(2.66)$ & $3.13^{* *}$ \\
Depression & $10.71(3.84)$ & $12.64(4.12)$ & $2.61^{* *}$ \\
Well B eing & $25.29(3.84)$ & $23.36(4.12)$ & $2.61^{* *}$ \\
\hline
\end{tabular}

$*_{p}=0.05, *_{p}=0.01, * *_{p}=0.001$

(C) The International Journal of Indian Psychology, ISSN 2348-5396 (e)| ISSN: 2349-3429 (p) | 36 


\section{Well Being, Psychosocial Problems and Social Interaction Anxiety in Children}

The groups formed were categorized as A and B with group A having low level of social interaction anxiety and group B having high level of social interaction anxiety. As seen in table 2, there was a significant difference in the level of emotional problems with those in group B showing higher level of emotional problems than those in group A. The participants in Group B also had higher peer problems than those in Group A. Comparing the level of overall internalizing problems, those in Group B had significantly higher problems than those in Group A.

The level of hyperactivity was significantly higher in Group B, that is, the group with high level of social interaction anxiety compared to Group A, which is the group with low level of social interaction anxiety. The difference in the level of conduct problems was not significant between Group A and Group B. However, the overall externalizing problems were higher in Group B than in Group A.

The role of social interaction anxiety was significant on depression with children in Group B having higher level of depression than children in Group A. In line with this, those in Group B had lower well being than those in Group A.

Table 3.

Correlation table of social interaction anxiety

\begin{tabular}{lc}
\hline & correlation \\
Emotional problems & $0.34^{* * *}$ \\
Peer problems & $0.21^{*}$ \\
Intemalizing Problems & $0.37^{* * *}$ \\
Hyperactivity & $0.29^{* *}$ \\
Conduct Problems & 0.15 \\
Extemalizing Problems & $0.29^{* * *}$ \\
Well Being & $-0.26^{* *}$ \\
Depression & $0.26^{* *}$ \\
\hline
\end{tabular}

${ }^{*} p=0.05, * * p=0.01, * * *_{p}=0.001$

Table 3 shows that social interaction anxiety was found to have significant correlation with emotional problems. The correlation between social interaction anxiety and peer problems was also significant. There was a significant correlation between social interaction anxiety with internalizing problems. Social interaction anxiety was found to be significantly correlated with hyperactivity. However, there was no significant correlation that was found between social interaction anxiety and conduct problems. But the overall correlation between externalizing problems with social interaction anxiety was significant. The correlation between social interaction anxiety and depression was also significant. 


\section{Well Being, Psychosocial Problems and Social Interaction Anxiety in Children}

\section{DISCUSSION}

The study was carried out to see if the type of care in terms of home based care and institutional care had a role in social interaction anxiety in children and results showed that there was a difference in the levels of social interaction anxiety among the children. Children in institutional care had higher levels of social interaction anxiety than those children who were residing with their parents at home. There are multiple factors that could have played a role in the higher levels of social interaction anxiety among institutionalized children. Institutions are characterized by strict and structured environment. Children are expected to adhere to all the rules of the institution where they are residing and there is a lot of control over the children's behaviour. There is limited freedom and autonomy for the children to act and behave in ways that they wish to. As mentioned earlier, controlling behaviour of parents has an impact on social anxiety in children. So a controlled environment in the institution may perhaps be contributing to social interaction anxiety in institutionalized children. Second, the children may feel that they are being evaluated or observed on their behaviour constantly by the adults around and there may not be unconditional acceptance of any mistakes they make. This apprehension about negative reaction to any erroneous behaviour on their part may lead to anxiety about interacting with others in a social situation (Erath, Flanagan and Bierman, 2007). Children living in institutions have limited opportunities for varied social experiences when compared to their peers who live at home. This could also make them apprehensive about how to interact with others in novel situations (Erath, Flanagan and Bierman, 2007). The belief about this lack of social experiences could further add to their anxiety about their ability to act in social situations. All these factors could be interacting with each other to explain the high levels of anxiety related to social interaction among institutionalised children.

Gender differences were also significant with girls showing markedly higher social interaction anxiety than boys. This is in line with existing research (Lewinsohn, Gotlib, Lewinsohn, Seeley and Allen, 1998; La Greca and Lopez, 1998) that has found that girls tend to display greater levels of anxiety than boys, particularly during adolescence.

Social interaction anxiety was found to be related to peer problems in adolescents with those having high social interaction anxiety displaying greater peer problems. Existing research supports this result (La Greca and Lopez, 1998). Negative social performance expectations, maladaptive coping strategies, and social skill deficits were examined among middle school children as possible correlates of social anxiety and mediators linking social anxiety with poor peer relations by Erath, Flanagan and Bierman (2007). Their study revealed correlations linking social anxiety with decreased peer acceptance and increased peer victimization in the children. When path analysis was used it was indicated that negative social performance expectations and social withdrawal-disengagement accounted for the relation between social anxiety and decreased peer acceptance. Social anxiety, self-directed coping strategies, and social withdrawal- 


\section{Well Being, Psychosocial Problems and Social Interaction Anxiety in Children}

disengagement were each found to be directly linked with increased peer victimization among boys.

Emotional problems among adolescents were found to be associated with social interaction anxiety in this study, which is consistent with results from other studies as well. There was an association found between social interaction anxiety and depression as well in the present study. There was also a negative influence of social interaction anxiety on the well being of adolescents (Ginsburg, La Greca and Silverman, 1998). In India, the age of passing out from institutional care differs depending on the policies of the institution itself. So children may pass out after they complete $10^{\text {th }}$ grade and move to another institution. Or in most cases they live in the institution till they attain adulthood, that is, eighteen years of age. Children in institutions, as they are growing older, become aware of the fact that in a few years they will no longer be part of the sheltered environment of the institution. Social interaction anxiety in these children may make them feel inadequate and incompetent leading to depression, poor well being and other emotional problems.

In the present study social interaction anxiety had a role in hyperactivity as well, with a strong correlation being found between the two. Children high on social interaction anxiety were also high on hyperactivity levels. This is an interesting finding as current research has not looked into this aspect and it has not been explored in existing research. As there has been only a correlation found between the two in the present study and no causation we cannot state if hyperactivity is causing social interaction anxiety among the adolescents or vice versa. But this association brings forth the possibility of using interventions that have worked on management of one to bring about a change in the other as well.

The present study is limited by its small sample which precludes generalizations of the findings of the study. Another hidden factor related to social interaction anxiety may be peer victimization or bullying which has not been explored in this study. But adolescence is an age where it is highly prevalent. At the same time, these findings cannot be ignored as they highlight the needs of children and adolescents.

\section{CONCLUSION}

India is a country that prides itself on its social affiliations and associations. A lot of importance is given to the ability to navigate social situations well and social skills are encouraged from a young age. In such a scenario the feeling of not being able to interact with others and the ensuing anxiety causes immense emotional distress to the adolescents in question. The common belief is that children learn social skills by observation and over a period of time acquire the necessary social behaviour that will stand them in good stead in future. In the case of institutionalised children this is not available as they do not get many opportunities to interact outside the institutional environment. 


\section{Well Being, Psychosocial Problems and Social Interaction Anxiety in Children}

The present study findings show that institutionalized children have higher levels of social interaction anxiety than non institutionalised children and this anxiety is corelated with psychosocial problems. Higher levels of social interaction anxiety were found to be associated with higher emotional problems, hyperactivity, peer problems and lower well being. This suggests that efforts directed towards tackling social interaction anxiety in children are required and may lead to a reduction in psychosocial problems and improve well being.

A concentrated effort has to be made to teach appropriate social skills (Fisher, Masia-Warner \& Klein, 2004) to children particularly those who are under institutional care. A psychosocial intervention with a multipronged approach involving multiple stakeholders would be beneficial for institutionalised children. Firstly, the caretakers at the institution need to be aware of social interaction anxiety and that it needs to be identified and addressed and for this they need to be provided with psycho-education. Counseling for children with social inetarction anxiety is also required. At the same time, social skills development programme for institutionalized children have to be implemented. Programs targeting creation of awareness in the caretakers/supervisors in the institutions in this area, and programs aimed at improving the interactional skills of institutionalised children appear to be essential.

\section{Acknowledgments}

The author appreciates all those who participated in the study and helped to facilitate the research process.

\section{Conflict of Interests}

The author declared no conflict of interests.

\section{REFERENCES}

Aangan Trust (2010). Annual Report March 2009- March 2010, Aangan India, Mumbai Retrieved on December 15, 2012 from http://aanganindia.org/pdf/Annual\%20Report2009-2010.pdf

American Psychological Association (2014). Anxiety. Retrieved from http://www.apa.org/topics/anxiety/ on 1st June 2014

Attar-Schwartz, S. (2007). Emotional behavioral and social problems among Israeli children in residential care: A multi-level analysis. Children and Youth Services Review, 30(2), 229248. doi:10.1016/j.childyouth.2007.09.009

Bandelow, B., Torrente, A. C., Wedekind, D., Broocks, A., Hajak, G., \& Rüther, E. (2004). Early traumatic life events, parental rearing styles, family history of mental disorders, and birth risk factors in patients with social anxiety disorder. European Archives of Psychiatry and Clinical Neuroscience, 254(6), 397-405

Biederman, J., Hirshfeld-Becker, D. R., Rosenbaum, J. F., Hérot, C., Friedman, D., Snidman, N., Kagan, J., \& Faraone, S. V. (2001). Further evidence of association between behavioral 


\section{Well Being, Psychosocial Problems and Social Interaction Anxiety in Children}

inhibition and social anxiety in children. The American Journal of Psychiatry, 158(10), 1673-1679.

Birleson, P. (1981). The validity of Depressive Disorder in Childhood and the Development of a Self-Rating Scale; a Research Report. Journal of Child Psychology and Psychiatry, 22: 73-88. doi: 10.1111/j.1469-7610.1981.tb00533.xBogels and Brechman-Toussaint, 2006).

Bohlin, G., Hagekull, B., \& Rydell, A. (2000). Attachment and Social Functioning: A Longitudinal Study from Infancy to Middle Childhood. Social Development, 9(1), 24-39. doi: 10.1111/1467-9507.00109

Browne, K. (2009). The risk of harm to young children in institutional care. London, Save the Children UK. Retrieved on December 15, 2012 from http://www.crin.org/docs/The_Risk_of_Harm.pdf

Caspi, A., Elder, G. H., \& Bem, D. J. (1988). Moving away from the world: Life-course patterns of shy children. Developmental Psychology, 24(6), 824-831. doi: 10.1037/00121649.24.6.824

Chisholm, K. (1998). A three year follow up of attachment and indiscriminate friendliness in children adopted from Romanian orphanages. Child Development, 69(4), 1092-106.

Egelund, T. \& Lausten, M. (2009). Prevalence of mental health problems among children placed in out-of-home care in Denmark. Child \& Family Social Work Special Issue: High Risk Youth: Evidence on Characteristics, Needs and Promising Interventions, 14 (2), 156-165. doi:10.1111/j.1365-2206.2009.00620.X

Erath, S. A., Flanagan, K. S., \& Bierman, K. L. (2007). Social Anxiety and Peer Relations in Early Adolescence: Behavioral and Cognitive Factors. Journal of Abnormal Child Psychology, 35(3), 405-416

Erol, N., Simsek, Z., \& Münir, K. (2010). Mental health of adolescents reared in institutional care in Turkey: challenges and hope in the twenty-first century. European Child and Adolescent Psychiatry, 19(2), 113-124. doi: 10.1007/s00787-009-0047-2

Festa, C. C. \& Ginsburg, G. S. (2011). Parental and peer predictors of social anxiety in youth. Child Psychiatry \& Human Development, 42(3), 291-306

Fisher, P. H., Masia-Warner, C., \& Klein, R. G. (2004). Skills for social and academic success: A school-based intervention for social anxiety disorder in adolescents. Clinical Child and Family Psychology Review, 7(4), 241-249

Ford, T., Vostanis, P., Meltzer, H. \& Goodman, R. (2007). Psychiatric disorder among British children looked after by local authorities: comparison with children living in private household. The British Journal of Psychiatry, 190, 319-325. doi:10.1192/bjp.bp.106.025023

Ginsburg, G. S., La Greca, A. M., \& Silverman, W. K. (1998). Social anxiety in children with anxiety disorders: Relation with social and emotional functioning. Journal of Abnormal Child Psychology, 26(3), 175-185.

Goodman, R. (1997). The Strengths and Difficulties Questionnaire: A Research Note. Journal of Child Psychology and Psychiatry, 38, 581-586 


\section{Well Being, Psychosocial Problems and Social Interaction Anxiety in Children}

Greco, L. A., \& Morris, T. L. (2002). Paternal child-rearing style and child social anxiety: Investigation of child perceptions and actual father behavior. Journal of Psychopathology and Behavioral Assessment, 24(4), 259-267

Karevold, E.,Ystrom, E., Coplan, R. J., Sanson, A. V., \& Mathiesen, K. S. (2012). A Prospective Longitudinal Study of Shyness from Infancy to Adolescence: Stability, Age-Related Changes, and Prediction of Socio-Emotional Functioning. Journal of Abnormal Child Psychology, 40(7), 1167-1177

Kashdan, T. B., \& Herbert, J. D. (2001). Social Anxiety Disorder in Childhood and Adolescence: Current Status and Future Directions. Clinical Child and Family Psychology Review, 4(1), 37-61

La Greca, A. M., Lopez, N. (1998). Social anxiety among adolescents: linkages with peer relations and friendships. Journal of Abnormal Child Psychology, 26(2), 83-94.

Lewinsohn, P. M., Gotlib, I. H., Lewinsohn, M., Seeley, J. R., \& Allen, N. B. (1998). Gender differences in anxiety disorders and anxiety symptoms in adolescents. Journal of Abnormal Psychology, 107(1), 109-117. doi: 10.1037/0021-843X.107.1.109

Lindhout, I. E., Markus, M. T., Hoogendijk, T. H. G., Boer, F. (2009). Temperament and parental child-rearing style: unique contributions to clinical anxiety disorders in childhood. European Child \& Adolescent Psychiatry, 18(7), 439-446

Mattick, R. P., \& Clarke, J. C. (1998). Development and validation of measures of social phobia scrutiny fear and social interaction anxiety. Behaviour Research and Therapy, 36(4), 455-470, http://dx.doi.org/10.1016/S0005-7967(97)10031-6

Morrison, A. (2008). An Exploration of Caregivers' Perceptions Regarding The Emotional Development Of 6-10-Year-Old Children Living In A Johannesburg Institution. (Masters Dissertation). Retrieved from WITS Institutional Repository on DSpace (WIReDSpace). (2010-06-22T06:07:47Z)

Mullan, C., McAlister, S., Rollock, F., \& Fitzsimons, L. (2007). 'Care just changes your life’: Factors impacting on the mental health of children and young people in care in Northern Ireland. Child Care in Practice, 13(4), 417-434. doi:10.1080/13575270701488865

Muris, P., Schmidt, H., \& Merckelbach, H. (2001). Correlations among two self-report questionnaires for measuring DSM-defined anxiety disorder symptoms in children: the Screen for Child Anxiety Related Emotional Disorders and the Spence Children's Anxiety Scale. Personality and Individual Differences, 28(2), 333-346

Nelson, C. A., Zeanah, C. H., Fox, N. A., Marshall, P. J., Smyke, A. T. \& Guthrie, D. (2007). Cognitive recovery in socially deprived young children: The Bucharest Early Intervention Project. Science, 21; 318(5858), 1937-1940, doi:10.1126/science.1143921

Ollendick, T. H., \& Benoit, K. E. A Parent-Child Interactional Model of Social Anxiety Disorder in Youth. Clinical Child and Family Psychology Review, 15(1), 81-91 


\section{Well Being, Psychosocial Problems and Social Interaction Anxiety in Children}

Phillips, D., McCartney, K., \& Scarr, S. (1987). Child-care quality and children's social development. Developmental Psychology, 23(4), 537-543. doi: 10.1037/00121649.23.4.537

Rutter, M., Colvert, E., Kreppner, J., Beckett, C., Castle, J., Groothues, C.,... Sonuga-Barke, E. J. (2007). Early adolescent outcomes for institutionally deprived and non-deprived adoptees I: Disinhibited attachment. Journal of Child Psychology and Psychiatry, 48(1), 17-30. doi: 10.1111/j.1469-7610.2006.01688.x

Simşek, Z., Erol, N., Oztop, D., \& Ozer Ozcan, O. (2008). Epidemiology of emotional and behavioral problems in children and adolescents reared in orphanages: A national comparative study. Turk Psikiyatri Dergisi (Turkish Journal of Psychiatry), 19(3), 235246.

Sushma, B., Padmaja, G., \& Agarwal, S. (2014). Internalizing problems, externalizing problems and depression among children under institutional care. Journal of Psychosocial Research, 9(1), 45-54.

van IJzendoorn, M. H., Luijk, M. P. C. M., \& Juffer, F. (2008). IQ of children growing up in children's homes a meta-analysis on IQ delays in orphanages. Merrill-Palmer Quarterly, 54(3), 341-366, doi: 10.1353/mpq.0.0002

Zeanah, C. H., Smyke, A. T., Koga, S. F., Carlson, E. \& The Bucharest Early Intervention Project Core Group. (2005). Attachment in institutionalized and community children in Romania. Child Development, 76(5), 1015-1028. doi:10.1111/j.1467-8624.2005.00894.x

How to cite this article: B Sushma, G Padmaja, S Agarwal (2016), Well Being, Psychosocial Problems and Social Interaction Anxiety in Children, International Journal of Indian Psychology, Volume 3, Issue 4, No. 59, ISSN 2348-5396 (e), ISSN: 2349-3429 (p), DIP: 18.01.060/20160304, ISBN: 978-1-365-26307-1 